\title{
STENTING IN MALIGNANT OBSTRUCTION OF SUPERIOR VENA CAVA
}

Rajesh Shah, MBBS, MS, FRCS Sabaratnam Sabanathan, DM, FRCS, FICA

Roger A. Lowe, MRCP, FRCR

Alan J. Mearns, FRCS
The treatment of patients with malignant superior vena caval obstruction with minimal morbidity has been made possible by the recent introduction of expandable metal stents as the sole palliative treatment or as an adjunct to other treatment modalities. To alleviate the distressing symptoms of superior vena caval obstruction, self-expanding metal stents were used successfully in 12 (Wallstent device in 6 and Gianturco device in 6 patients) of 13 patients. The diagnoses were small cell carcinoma $(n=4)$, squamous cell carcinoma $(n=4)$, non-Hodgkin's lymphoma $(n=1)$, and mesothelioma $(n=1)$, and a diagnosis of malignancy was not confirmed (although strongly suspected) in the remaining three cases. Eleven patients had immediate relief of obstruction and there was no change in one patient. Mean follow-up was 3.7 months (range 1 to 10 months). Excellent palliation was obtained in all but one patient in whom recurrent superior vena caval obstruction developed 3 months after stenting. Mean survival was 4.8 months (range 1 to 10 months). The ease of insertion with the use of local anesthesia with radiologic control, the self-expanding nature of the stent, and the lack of major complications on follow-up of up to $\mathbf{1 0}$ months are particular advantages. The self-expanding superior vena caval stents are a useful addition to our armamentarium in the management of malignant superior vena caval obstruction. (J Thorac Cardiovasc Surg 1996; 112:335-40)
Quperior vena caval (SVC) syndrome was first de$\mathcal{O}_{\text {scribed by William Hunter in } 1757 .{ }^{1} \text { The SVC }}$ syndrome is caused by malignant disease in $85 \%$ to $95 \%$ of reported cases. ${ }^{2-4}$ The cause is bronchogenic carcinoma in about $80 \%$ of the cases, with lymphoma and metastatic disease comprising $15 \%$ and $5 \%$, respectively. ${ }^{4}$ Mediastinal inflammation as a result of fibrosing mediastinitis and granulomatous disease caused by histoplasmosis infection predominate the benign causes of SVC syndrome. ${ }^{4}$ With the advent of long-term central venous catheterization for diagnostic or therapeutic interventions, catheter-related thrombosis of the SVC is being increasingly reported. ${ }^{2,5}$

The symptoms consist of venous congestion and edema of the upper half of the body. The prognosis is poor in the presence of upper airway obstruction

From the Department of Thoracic Surgery, Bradford Royal Infirmary, Bradford, United Kingdom.

Received for publication June 1, 1995; accepted for publication Sept. 19, 1995.

Address for reprints: S. Sabanathan, DM, FRCS, FICA, Consultant Thoracic Surgeon, Department of Thoracic Surgery, Bradford Royal Infirmary, Duckworth Lane, Bradford BD9 6RJ, United Kingdom.

Copyright $\mathbb{C} 1996$ by Mosby-Year Book, Inc.

$0022-5223 / 96 \$ 5.00+0 \quad \mathbf{1 2 / 1 / 6 9 3 4 7}$ caused by edema or cerebral edema. ${ }^{3}$ Bypass operations, ${ }^{6}$ radiation therapy, ${ }^{7,8}$ and chemotherapy ${ }^{9}$ have been used to treat SVC syndrome. The indications for operation are limited, and radiation therapy and chemotherapy are not promptly effective. ${ }^{10}$ Recurrent SVC obstruction develops in $10 \%$ to $19 \%$ of the patients after radiotherapy. ${ }^{2}$ Surgical management is associated with high morbidity and mortality particularly in patients with malignant disease with a short life expectancy.

Percutaneous stent placement for the treatment of SVC obstruction has been previously reported with Gianturco stents ${ }^{11-15}$ (William Cook Europe AS, Bjaerverskov, Denmark), Palmaz stents ${ }^{16}$ (Johnson \& Johnson Interventional Systems, Warren, N.J.), and Wallstent devices ${ }^{17,18}$ (Schneider Inc., Pfizer Hospital Product Groups, Minneapolis, Minn.). We present our experience of 13 patients, updating our previous report of two cases. ${ }^{19}$

\section{Patients and methods}

Between May 1991 and March 1995, we placed selfexpanding metal stents in 13 consecutive patients with clinical evidence of SVC obstruction. There were eight men and five women, with a mean age of 60 years (range 52 to 74 years). Table I shows the demographic details of the patients and the causes of SVC obstruction. Eleven 
Table I. Demographic details

\begin{tabular}{|c|c|c|c|c|c|}
\hline Patient No. & Sexiage $(y r)$ & Diagnosis & Stent & Response & Follow-up \\
\hline 1 & $\mathrm{M} / 67$ & Small-cell carcinoma & Gianturco, 2 stents & Good & 10 months (died) \\
\hline 2 & $\mathrm{~F} / 60$ & $\mathrm{R}$ paratracheal mass & Gianturco & Good & 2 months (died) \\
\hline 3 & $\mathrm{M} / 79$ & $\mathrm{R}$ paratracheal mass & Gianturco, 2 stents & Poor & 1 month (died) \\
\hline 4 & $\mathrm{~F} / 58$ & Small-cell carcinoma & Gianturco, 2 stents & Good & 5 months (died) \\
\hline 5 & $\mathrm{M} / 64$ & NHL of mediastinum & Gianturco & Good & 6 months (died RTA) \\
\hline 6 & $\mathrm{M} / 71$ & $\mathrm{R}$ paratracheal mass & Gianturco, 4 stents & Good & 3 months (died) \\
\hline 7 & $\mathrm{M} / 74$ & $\begin{array}{l}\text { Recurrent squamous } \\
\text { cell carcinoma RUL }\end{array}$ & Wallstent & Good & 1 month \\
\hline 8 & $\mathrm{M} / 52$ & Mesothelioma & Wallstent & Good & $\begin{array}{l}\text { Recurrent SVC } \\
\text { obstruction } 3 \text { months }\end{array}$ \\
\hline 9 & $\mathrm{M} / 68$ & $\begin{array}{l}\text { Squamous cell carcinoma } \\
\text { mediastinum }\end{array}$ & Wallstent & Good & 3 months (died) \\
\hline 10 & $\mathrm{~F} / 58$ & $\begin{array}{l}\text { Squamous cell } \\
\text { carcinoma RMB }\end{array}$ & $\begin{array}{l}\text { Wallstent } \\
\text { (thrombolysis }+ \text { ) }\end{array}$ & Good & 5 months \\
\hline 11 & $\mathrm{~F} / 59$ & Small-cell carcinoma & Wallstent & Good & 1 month (died) \\
\hline 12 & $\mathrm{M} / 68$ & Small-cell carcinoma & Wallstent & Good & 5 months (died) \\
\hline 13 & $\mathrm{~F} / 63$ & $\begin{array}{l}\text { Squamous cell carcinoma } \\
\text { with mediastinal metastasis }\end{array}$ & Unsuccessful & - & 3 months (died) \\
\hline
\end{tabular}

$R$, Right; $N H L$, non-Hodgkin's lymphoma; $R T A$, road traffic accident; $R U L$, right upper lobe; $R M B$, right main bronchus.

patients had presenting symptoms of severe SVC obstruction, and two patients had recurrent SVC obstruction after radiotherapy. Patients with upper airways compromised by laryngotracheal edema or with symptoms caused by cerebral edema were considered to have severe SVC obstruction.

In all patients diagnosis was confirmed by venography (Figs. 1 and 2) before stenting. Histologic diagnosis of the cause of obstruction was confirmed by bronchoscopy or mediastinoscopy, or both, in 10 cases and in the remaining three cases histologic confirmation was not obtained despite high clinical and radiologic suspicion of malignancy.

Stent insertion with the use of a local anesthetic with radiologic control (see following section) was attempted in 13 patients and was technically successful in 12 patients. One patient needed thrombolytic treatment before stent placement. Six patients received Gianturco stents (earlier series) (Fig. 3) and the most recent six patients had Wallstent devices inserted (Fig. 4). Multiple Gianturco stents were used in five patients in the SVC and the left innominate vein. Six patients received additional radiotherapy or chemotherapy after stent insertion. Two patients had received radiotherapy previously and in the remaining five patients the condition was considered unsuitable for any additional treatment. Complete resolution of symptoms after stent placement was the criterion used to assess the success of the procedure. All patients were examined clinically by the thoracic surgeons and chest physicians.

Technique of insertion. The technique of stent placement has been documented, ${ }^{14,18}$ and only the salient points of the technique are summarized here.

1. Adequate demonstration of the relevant mediastinal venous anatomy is achieved with catheter placed from both arms.
2. A guide wire is negotiated across the stenosed or occluded SVC. This is generally achievable with use of a supporting catheter and hydrophilic guide wire combination familiar to interventional radiologists.

3 . The stent is placed across the stenosed or occluded segment ensuring adequate coverage of the lesion, with use of an appropriately sized angioplasty balloon to aid stent expansion when necessary. The use of a long, very stiff exchange wire greatly facilitates this stage of the procedure, preventing coiling in the right atrium and allowing enough length to accommodate the long stent delivery system.

4. A standard sized Wallstent device $12 \mathrm{~mm}$ in diameter and $9.6 \mathrm{~cm}$ long is adequate for all patients.

5. The accurate placement required in most arterial settings is less important in SVC obstruction because of the length and diameter of the vessel and the availability of effective collateral channels.

6. All patients receive 5000 units heparin before stent deployment and intravenous heparin $(24,000$ units/24 hours) for 48 hours.

7. Patients who required thrombolysis before stent placement receive long-term warfarin maintenance.

\section{Results}

The procedure was technically successful in 12 out of 13 cases, and failure was caused by complete occlusion of the SVC by extensive thrombus. In 10 patients immediate relief of SVC obstruction was seen within 24 to 48 hours, in one patient who had thrombolytic treatment previously clinical relief was not seen until 72 hours after stent placement, and in the remaining one patient clinical status remained unchanged. 
Mean follow-up was 3.7 months (range 1 to 10 months). Recurrent SVC obstruction occurred in only one patient (patient 8) 3 months after initial stent insertion. Repeat venogram showed thrombotic occlusion, which responded effectively to thrombolytic treatment and placement of a second Wallstent device within the original stent. Ten patients died during the follow-up period with a mean survival of 4.8 months (range 1 to 10 months).

\section{Discussion}

Various modalities of treatment have been advocated for the management of SVC obstruction. With recent advances in percutaneous interventional vascular technology thrombolytic agents, angioplasty, and intravascular stents have been used in the management of SVC obstruction. ${ }^{11-13,20-22}$ Conventional treatment of this condition has been by radiotherapy, although chemotherapy is of value in small cell carcinoma. ${ }^{23}$ Although radiotherapy is successful in relieving obstruction caused by sensitive tumors such as lymphoma the success rate with bronchial carcinoma is less consistent. ${ }^{3}$ Remission rates of $76 \%$ are quoted in such situations. ${ }^{24}$ Surgical procedures such as venous bypass grafts or pericardial grafts necessitate major operations in patients with limited life expectancy. ${ }^{4,25}$

The intraluminal self-expanding metallic stents can be placed percutaneously under local anesthesia with radiologic control. The stent can be compressed and introduced through a Teflon polytetrafluoroethylene catheter sized $8 \mathrm{~F}$ to $12 \mathrm{~F}$ depending on the caliber of the wire and the diameter of the stent. When the stent is released from the catheter, it expands to its original diameter. The expansion force varies with the caliber of the wire, the diameter and the length of the stent, and the number and angle of the bends. ${ }^{26}$ When placed in the venous system, stents gradually are covered by the tunica intima and incorporated into the vascular wall within a few weeks, without impairing the patency of the side branches. ${ }^{11}$ The length of the stenosis does not preclude stent insertion because multiple stents can be inserted at the same time as in this series. For long strictures that require multiple stents, the distal stent should be placed first. The major disadvantage of the Gianturco stent used in the early part of this series is its shorter length and its potential to allow tumor ingrowth through its wider gap between the stent wires. The Wallstent device maintains the advantage of the metal stent, and its narrow woven mesh, greater flexibility, and

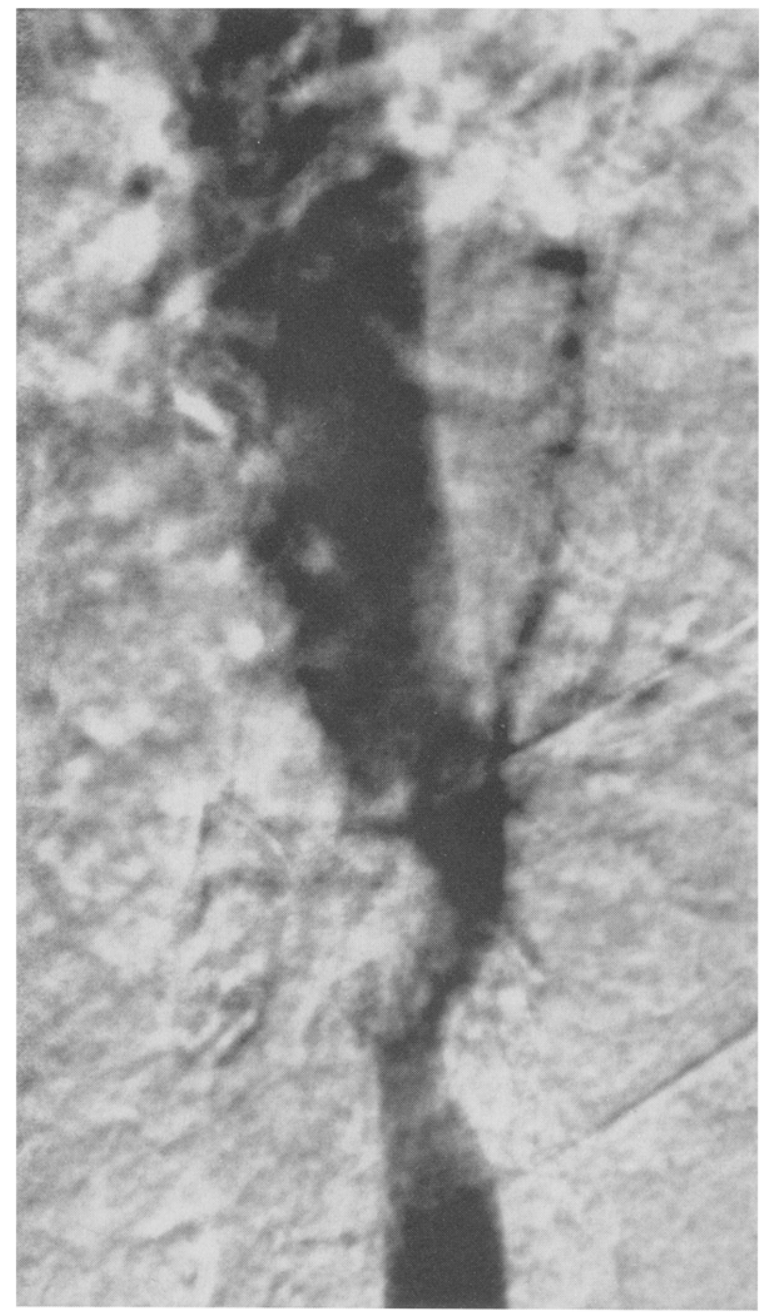

Fig. 1. Digital subtraction venogram in patient with SVC obstruction.

longer length make it superior to the Gianturco stent.

Patients who are unable to lie flat, those with chronic complete vessel occlusion or severe coagulopathy, and those with cardiac failure are unsuitable candidates for intravascular stent placement. ${ }^{27,28}$ Pulmonary edema because of a sudden increase in venous return after SVC stent placement has been reported. ${ }^{29}$ For SVC obstruction caused by benign diseases the stent insertion should be approached with caution. It should only be considered in patients in whom other techniques of palliation have failed or are hazardous. The follow-up to date after such procedures in these patients has been relatively short. However, restenosis as a result of 


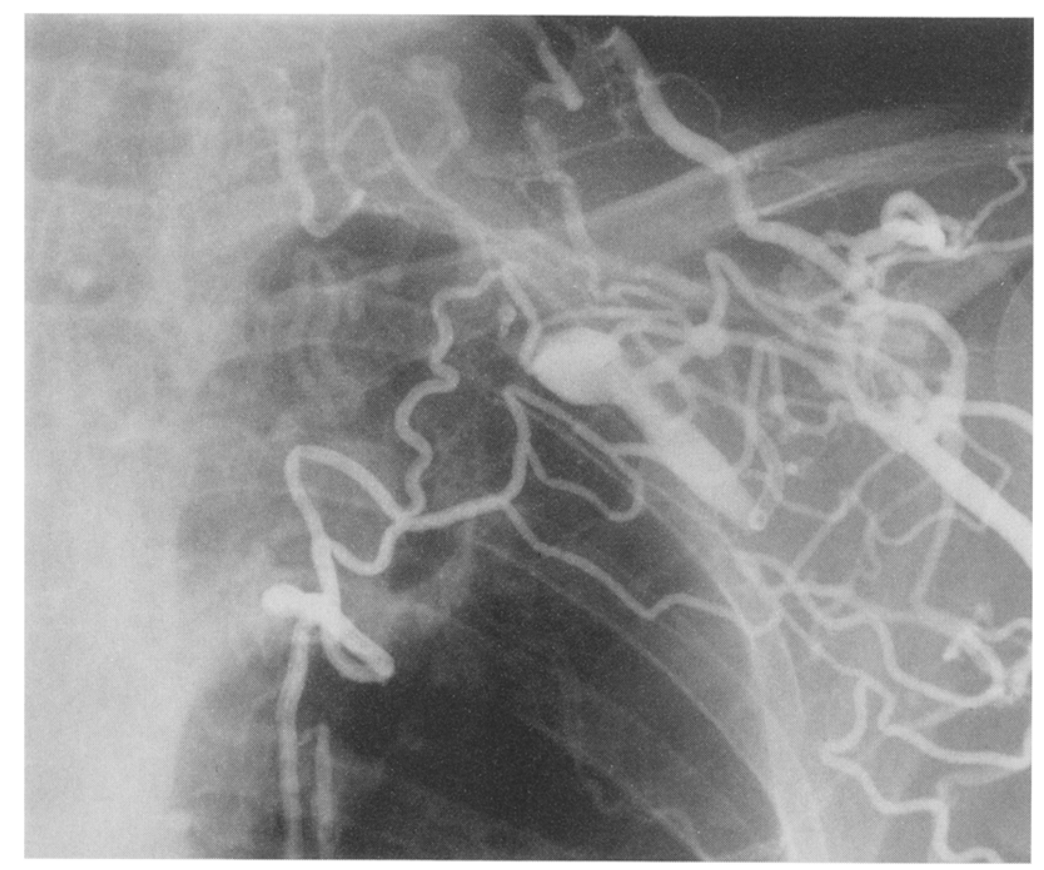

Fig. 2. Venogram demonstrating complete obstruction of SVC and brachiocephalic veins.

epithelial hyperplasia would not preclude palliation by other means. ${ }^{14}$

We have demonstrated a failure rate of $7.1 \%$ with the Gianturco stent with no restenosis. This compares favorably with the failure rate of $7.7 \%$ and restenosis rate of $14.3 \%$ reported in 91 patients in the literature. ${ }^{14,16,27,28-30}$ There have been fewer reports on the use of the Wallstent device. Reported rates of failure and restenosis after Wallstent device insertion are $0 \%$ and $9 \%$, with the corresponding rates for our patients in this series at $0 \%$ and $16.6 \%$, respectively. ${ }^{18,31}$

In a recent review of 56 procedures for relief of SVC obstruction a morbidity rate of $29 \%$ and a mortality rate of $4 \%$ were observed. ${ }^{27}$ The reported complications were stent misplacement $(10 \%)$, stent occlusion (10\%), stent migration (5\%), and chest pain $(4 \%) .{ }^{27}$ In this series thrombotic stent occlusion was the only complication seen in one patient (patient 8) and there was no stent-related mortality. Cardiac arrhythmias and stent breakage have also been reported. ${ }^{27}$ The antagonistic movements of cardiac contraction, diaphragmatic excursion, and tumor compression probably contribute to the mechanism of breakage. ${ }^{27}$

The stents are thrombogenic and it was initially thought that patients required a short period of anticoagulation. Rosch and associates ${ }^{12}$ used longterm anticoagulation routinely, whereas Irving and colleagues $^{14}$ did not. However, both groups had almost identical long-term patency rates. In one patient in our series thrombotic occlusion occurred, which was effectively treated by thrombolytic treatment and placement of a second stent. Anticoagulation therapy after a stent procedure is indicated if there is a risk of thromboembolism. However, the benefits of this measure should be weighed against the risk of bleeding complications and inconvenience to terminally ill patients. If thrombus is present initially, it should be lysed before stent placement, as in patient 10 in our series. ${ }^{28,32}$ Follow-up periods of up to 1 year in SVC stents and 2 years in inferior vena caval stents have demonstrated long-term patency of these devices. ${ }^{27}$ In our series the stent was patent up to 10 months after insertion in patient 1 .

From our experience and that of others ${ }^{12,27}$ there is no doubt that stenting is an effective treatment for SVC obstruction. What remains to be decided is the timing of the the treatment. Certainly stenting should be the treatment of choice in unrelieved obstruction after treatment and in patients with recurrent obstruction after initially successful treatment and even as a primary treatment modality for 


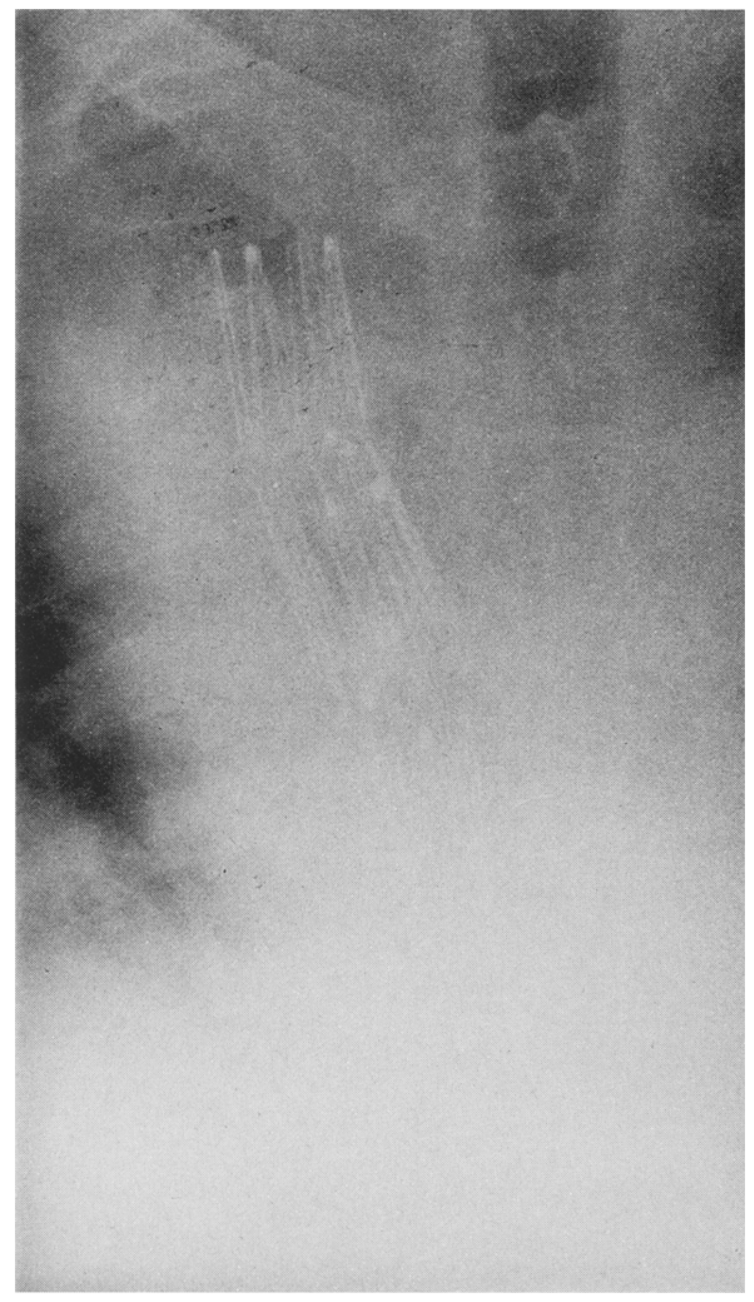

Fig. 3. Chest radiograph showing Gianturco stent in SVC (same patient as in Fig. 1).

patients who are unfit or in those with threatened cerebral and laryngeal edema. It is a simple, safe, rapidly effective, minimally invasive technique for management of SVC obstruction.

\section{REFERENCES}

1. Parish JM, Marschke RF, Dines DE, Lee RE. Etiologic considerations in SVC syndrome. Mayo Clin Proc 1981;56: 407-13.

2. Perez CA, Presant CA, Van Amburg AL III. Management of superior vena caval syndrome. Semin Oncol 1978;5:123-34.

3. Lochridge SK, Patrick K, Doty DB. Obstruction of superior vena cava. Surgery 1979;85:14-24.

4. Doty DB, Doty JR, Jones KW. Bypass of superior vena cava: fifteen years' experience with spiral vein grafts for obstruction of superior vena cava caused by benign disease. $J$ Thorac Cardiovasc Surg 1990;99:889-96.

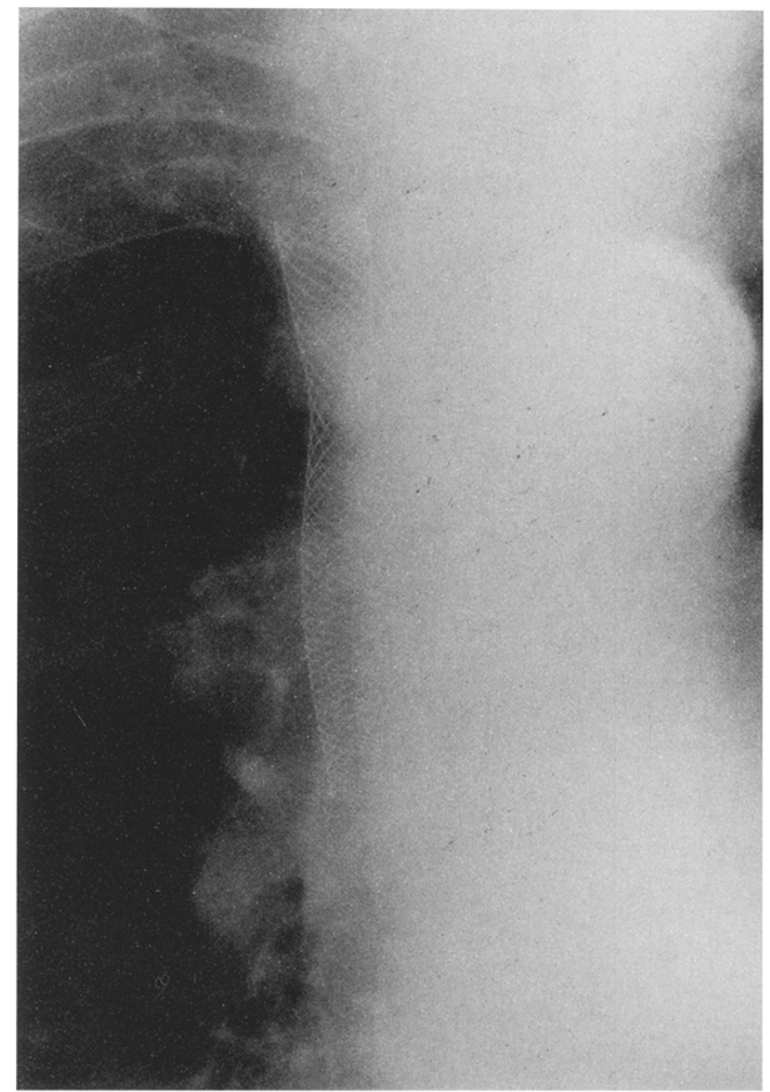

Fig. 4. Wallstent device in SVC (same patient as in Fig. 2).

5. Capek P, Cope C. Percutaneous treatment of superior vena caval syndrome. AJR Am J Roentgenol 1989;152:183-4.

6. Doty DB. Bypass of superior vena cava: six years' experience with spiral vein graft for obstruction of superior vena cava due to malignant disease. J Thorac Cardiovasc Surg 1982;83: 326-8.

7. Slawson RG, Prempree T, Viravathana T, et al. Radiation therapy for superior vena caval syndrome due to lung cancer. Maryland State Med J 1981;30:68-70.

8. Sakai K, Satoh T, Yamasaki M, Kitabatake T. The superior vena cava syndrome and its radiotherapy: clinical response and survival. Nippon Hoshasen Gakkai Zasshi 1973;33: 300-7.

9. Lokich J. Superior vena cava syndrome. In: Lokich JJ, editor. Clinical cancer medicine treatment tactics. Boston, Massiachusetts: GK Hall, 1980:381-91.

10. Chen JC, Bongard F, Klien SP. A contemporary perspective on superior vena cava syndrome. Am J Surg 1990;160:207-11.

11. Charnsangaveg $\mathrm{C}$, Carraso $\mathrm{CH}$, Wallace $\mathrm{S}$, et al. Stenosis of the vena cava: preliminary assessment of treatment with expandable metallic stents. Radiology 1986;161:295-8.

12. Rosch J, Bedell JS, Putnam J, Antovinic R, Uchida B. Gianturco expandable wire stents in the treatment of superior vena cava syndrome recurring after maximum tolerance radiation. Cancer 1987;600:1243-6. 
13. Putnam JS, Uchida BT, Antonivic R, Rosch J. Superior vena cava syndrome with massive thrombosis: treatment with expandable stents. Radiology 1988;167:727-8.

14. Irving JD, Dondelinger RF, Reidy JF, et al. Gianturco self expanding stents: clinical experience in vena cava and large veins. Cardiovasc Intervent Radiol 1992;15:328-33.

15. Quinn SF, Schuman ES, Lee Hall MC, et al. Venous stenosis in patients who undergo hemodialysis: treatment with self expanding endovascular stents. Radiology 1992;183:499-504.

16. Solomon N, Holey MH, Jarmolowski LR. Intravascular stents in the management of superior vena cava syndrome. Cathet Cardiovasc Diagn 1991;23:245-52.

17. Antonucci F, Salomonowitz C, Stuckmann G, et al. Placement of venous stents: clinical experience with a self expanding prosthesis. Radiology 1992;183:493-6.

18. Watkinson AF, Hansell DM. Expandable wall stent for the treatment of obstruction of the superior vena cava. Thorax 1993;48:915-20.

19. Eng J, Sabanathan S. Management of superior vena cava obstruction with self expanding intraluminal stents. Scand J Thorac Cardiovasc Surg 1993;27:53-5.

20. Palmaz J. Balloon expandable intravascular stent. AJR Am J Roentgenol 1988;150:1263-9.

21. Walpole H, Lovett K, Chaung U, West R, Clements S. Superior vena cava syndrome treated by percutaneous transluminal angioplasty. Am Heart J 1988;115:1303-4.

22. Sherry C, Diamond N, Meyers T, Martin R. Successful treatment of superior vena cava syndrome by venous angioplasty. AJR Am J Roentgenol 1986;147:834-5.
23. Spiro SG, Brewis RAL, Gibson GJ, Geddes DM. Respiratory medicine. Vol. 8. London: Boulliere Tindall, 1990:628-30.

24. Dyet JF, Moghissi K. Role of venography in assessing patients with superior vena caval obstruction caused by carcinoma for bypass operations. Thorax 1980;8:628-30.

25. Lemmer JH, Behrendt DM, Beekam RH, Hermendez RJ. Pedicled right atrial pericardial tissue conduit for bypass of the obstructed superior vena cava in children. J Thorac Cardiovasc Surg 1989;98:417-20.

26. Wright KC, Wallace S, Charnsagavej C, Carrasco HC, Gianturco C. Percutaneous endovascular stents: an experimental evaluation. Radiology 1985;156:69-72.

27. Oudkerk M, Heystraten FMJ, Stoter G. Stenting in malignant vena caval obstruction. Cancer 1993;71:142-6.

28. Gaines PA, Belli AM, Anderson PB, McBride K, Hemingway AP. Superior vena caval obstruction managed by the Gianturco Z stent. Clin Radiol 1994;49:202-8.

29. Kishi K, Sonomura T, Mitsuzane K, et al. Self-expandable metallic stent therapy for superior vena cava syndrome: clinical observations. Radiology 1993;189:531-5.

30. Rosch J, Uchida BT, Hall LD, et al. Gianturco-Rosch expandable Z-stents in the treatment of superior vena caval obstruction. Cardiovasc Intervent Radiol 1992;15:319-27.

31. Dyet JF, Nicholson AA, Cook AM. The use of Wallstent endovascular prosthesis in the treatment of malignant obstruction of the superior vena cava. Clin Radiol 1993;48: 381-5.

32. Wright KC. Percutaneous transcatheter stent placement. Radiology 1990;176:620-1. 